\title{
A nondestructive stratigraphic and radiographic neutron study of Lorenzo Ghiberti's reliefs from paradise and north doors of Florence baptistery
}

\author{
G. Festa, ${ }^{1, a)}$ C. Andreani, ${ }^{1}$ M. P. De Pascale, ${ }^{1}$ R. Senesi, ${ }^{1}$ G. Vitali, ${ }^{1}$ S. Porcinai, ${ }^{2}$ \\ A. M. Giusti, ${ }^{2}$ R. Schulze, ${ }^{3}$ L. Canella ${ }^{4}$ P. Kudejova, ${ }^{3,4}$ M. Mühlbauer, ${ }^{5}$ B. Schillinger, ${ }^{5}$ \\ and the Ancient Charm Collaboration ${ }^{b}$ \\ ${ }^{1}$ Dipartimento di Fisica and Centro NAST (Nanoscienze, Nanotecnologie \& Strumentazione), \\ Università degli Studi di Roma Tor Vergata, Via della R. Scientifica 1, 00133, Rome, Italy \\ ${ }^{2}$ Opificio delle Pietre Dure, Viale Strozzi 1, 50129, Florence, Italy \\ ${ }^{3}$ Institute for Nuclear Physics, University of Cologne, Zülpicher Str. 77, 50937 Köln, Germany \\ ${ }^{4}$ Institute for Radiochemistry, Technische Universität München, Walther-Meißner-Str. 3 \\ D-85748 Garching, Germany \\ ${ }^{5}$ Forschungsneutronenquelle Heinz Maier-Leibnitz, (FRM II)/Physikdepartment E21, \\ Technische Universität München, Lichtenbergstraße 1, 85747 Garching, Germany
}

(Received 2 April 2009; accepted 14 July 2009; published online 13 October 2009)

\begin{abstract}
A neutron study on two gilded bronze reliefs by Lorenzo Ghiberti is presented. The two reliefs, representing heads of prophets, come from the north and east doors of the Baptistery of Florence. The east door will be permanently located at the Museo dell'Opera di Santa Maria del Fiore museum at the end of its restoration, which is still in progress at the Metals Conservation Department of the Opificio delle Pietre Dure in Florence. The north door is kept in the original site, on the north facade of the Florentine Baptistery. Both reliefs exhibit critical aspects regarding their state of conservation in particular the stability of the gold layer on the bronze surface. Moreover the east head presents a remelting of which extension and composition are still unknown. The present work describes a non-destructive study of the subgilding area and bulk. The two main objectives of such analyses are: (1) to study the manufacturing technique and state of conservation of the reliefs; and (2) to assess the two cleaning techniques (laser cleaning and Rochelle salts chemical cleaning) used by the conservators during the restoration process of the east door. The experiment was carried out using prompt gamma-ray activation imaging combined with neutron radiography and conventional neutron radiography. The former method was applied to map the elemental composition of the two reliefs, while neutron radiography was used to investigate the bulk. The results provide significant information about subsuperficial areas, elemental composition of the objects from the surface down to a depth of $1 \mathrm{~mm}$ below gilding, and bulk structure of the remelting. Such information will guide the curators in the selection of the most suitable microclimatic conditions for the exhibition of the east door and for future conservation work on the north door. (C) 2009 American Institute of Physics. [doi:10.1063/1.3204514]
\end{abstract}

\section{INTRODUCTION}

The gilded bronze reliefs under investigation are part of the east and north doors of the Baptistery of Florence made by Lorenzo Ghiberti (1378-1455). The doors are considered to be among the most important masterpieces of metallurgical art from the Renaissance. The east door, known as Porta del Paradiso, is composed by ten gilded bronze panels representing scenes from the Old Testament surrounded by a frame made of gilded bronze medallion and high-relief busts. Since the early 1990s, because of damage from the 1966 Florence flood, the east door has been under restoration at the Metals Conservation Department of the Opificio delle Pietre Dure in Florence. Restoration work is due to be completed by the end of 2009. A critical aspect concerning the state of conservation regard the chemical and physical stabilities of the gold layer on the bronze alloy. The advanced deterioration state of the mercury-amalgam gilded sculptures

\footnotetext{
a)Electronic mail: giulia.festa@roma2.infn.it.

${ }^{b}$ URL: http://ancient-charm.neutron-eu.net/ach.
}

suggested specific strategies for urgent restoration, especially addressing suitable cleaning treatments. The gilding technique and stratigraphic structure of the doors have been assessed by previous investigations ${ }^{1-4}$ showing that copper corrosion compounds (i.e., copper oxides, chlorides, and sulfates) are located immediately below the gold layer. The gilding is also covered by encrustations due to a mixture of corrosion products and deposits (gypsum, quarts, feldspars, carbon, etc.) as a result of the interaction with the outdoor environment. Additionally, copper corrosion below the gilding produces excrescences, pitting, and in some cases microlifting, which have damaged the gold layer. As a consequence oxide and salt layers constitute the current "bed" of the gold layer, requiring special attention from a restoration point of view. As a matter of fact restoration over the last 20 years has focused on selectively removing some of the corrosion compounds under the gold layer and the black crusts above it while preserving the stable substrate of copper oxides supporting the gold layer. In the case of the east door two types of cleaning methods were chosen: a chemical 


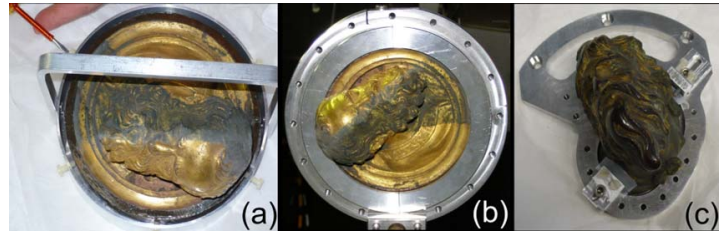

FIG. 1. (Color online) Gilded reliefs in their own sample holders. (a) east head for the PGAI measurements; (b) east head for the NR measurements; (c) north head for the PGAI and NR measurements. In (b), from top to bottom, three areas with different cleaning procedures are visible: chemical agent, uncleaned and the laser ablation.

agent bath (Rochelle salt solution-sodium potassium tartrate) and laser ablation. ${ }^{5-7}$

This paper presents a noninvasive and nondestructive experimental neutron study of the internal structure and elemental composition of subsurface corrosion compounds at the gilding/alloy interface of two gilded bronze reliefs (the heads). Aim of the study is to investigate both manufacturing technique and state of conservation of the reliefs and, in the case of the east head, the effectiveness of the two cleaning techniques (cleaning laser and chemical agents) used for restoration during the conservation process. For the latter sample neutron analysis was applied to three distinct areas of the east head, an uncleaned area and the two areas treated with different cleaning procedures. Moreover this sample was investigated through neutron radiography (NR) in order to further identify the extension of the east head remelting area, and the bulk structure.

\section{EXPERIMENT}

The prompt gamma-ray activation imaging combined with neutron radiography (PGAI/NR) experiment was carried out at the prompt gamma activation analysis (PGAA) station at the FRM II reactor (Garching, Munich, Germany) employing PGAI/NR. This method was developed within the Ancient Charm European Project. ${ }^{8-11}$ An additional investigation of the two reliefs was performed using high resolution NR. Figures 1 shows the samples positioned in their sample holders [Figs. 1(a) and 1(b): east head and Fig. 1(c): north head].

\section{A. Two-dimensional-PGAI/NR at PGAA station}

A set of measurements was performed in order to map the elemental composition of the two reliefs, along and through the surfaces, down to approximately $1 \mathrm{~mm}$ in depth, with a neutron exposure allowing for a sample deactivation time of three days, to comply with the shipping of the two samples back to Florence which was scheduled 5 days after the neutron measurements.

Using PGAA the elemental composition of an irradiated volume was determined, while simultaneous neutron radiographies provided information about the internal morphology of the two reliefs, as well as guiding the positioning of the incident neutron beam. A diagram of the PGAI/NR setup employed is shown in Fig. 2: a camera-based detector is placed in transmission mode behind the sample and the

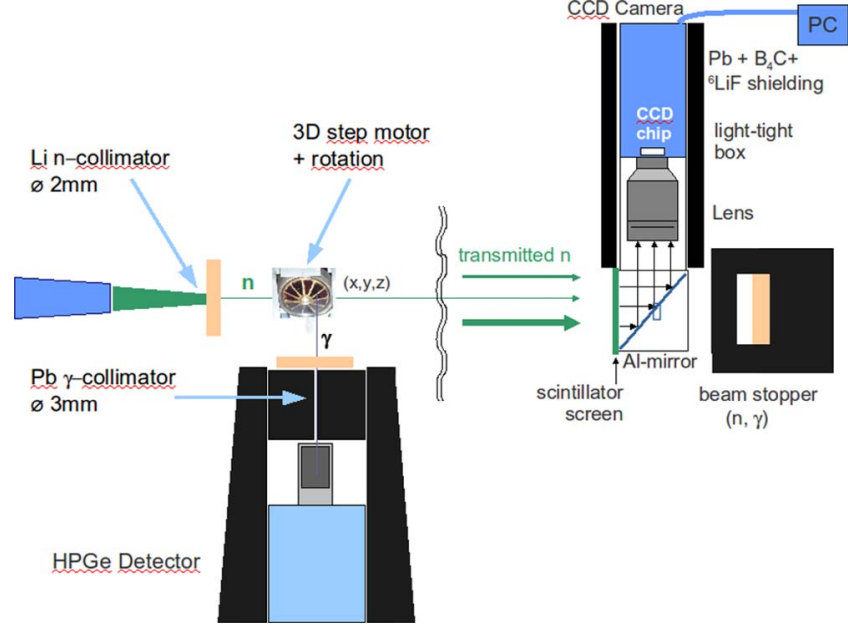

FIG. 2. (Color online) Scheme of the PGAI/NT setup on the PGAA station at the FRMII reactor (Ref. 13).

PGAI gamma-collimated detector is mounted at $90^{\circ}$ relative to the incident beam. The measurement area used for PGAI, called isocenter, is a geometrical locus defined by the intersection of a highly collimated neutron beam $\left(2 \times 2 \mathrm{~mm}^{2}\right)$ and the viewing angle of a highly collimated HPGe detector. The reliefs were placed on a $x y z-\omega$ goniometer in order to select the area under investigation for the neutron measurements. $^{12,13}$

The PGAI measurements were performed in a non standard configuration, using neutron collimation but no gamma collimation, in order to achieve higher count-rates in the detector thus reducing the irradiation time of the samples. Preliminary measurements were devoted to the estimation of the irradiation time to ensure adequate acquisition statistics and sample cooling time below $72 \mathrm{~h}$. PGAI measurements were performed on three selected areas of the east head and four selected points of the north head. For the east head the selected areas were those treated with different cleaning procedures, laser ablation and chemical agent (Rochelle salts), and an uncleaned one [see Fig. 1(b)]. The neutron beam was positioned tangentially to the surface of the area under investigation in order to probe layers of several hundreds of microns below the surface. This method allowed a unique re-

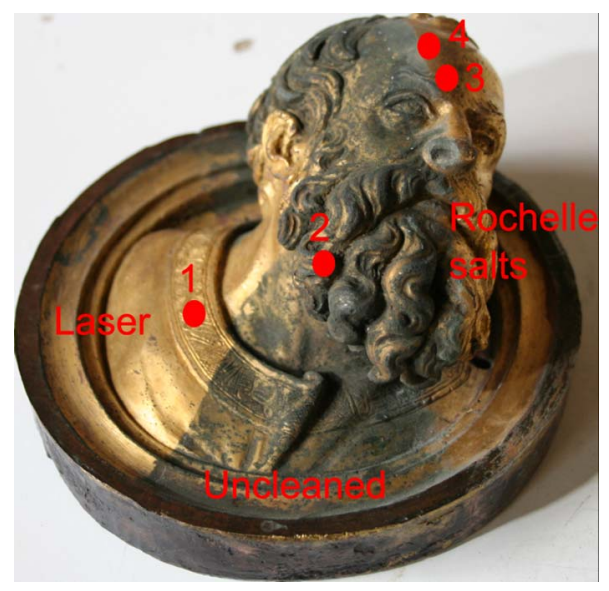

FIG. 3. (Color online) East head picture. The irradiated areas are labeled by numbers and corresponds to position label reported in Table I. 


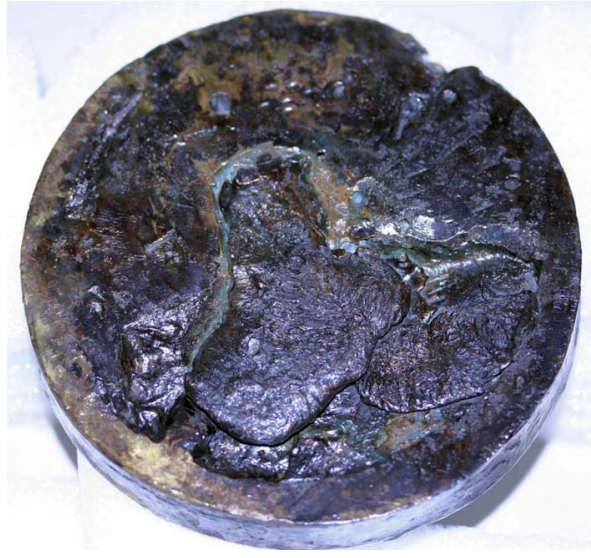

FIG. 4. (Color online) Lower side of the east head that presents an inhomogeneous remelted region.

construction of the composition of both heads down to a depth about $1 \mathrm{~mm}$ from the surface, which cannot be investigated nondestructively by other surface techniques, such as proton induced $\mathrm{x}$-ray emission or $\mathrm{x}$-ray fluorescence.

The setup for simultaneous NR measurements was designed in order to obtain an image of the irradiated area during each measurement. The sample positions on the east head investigated with PGAI/NR are shown in Fig. 3. For each position a set of several measurements was performed at different depths, starting from the surface. A step-motor system allows the positioning of the sample into the neutron beam and with steps of $0.25 \mathrm{~mm}$ the surface can be studied. A detailed description of this experimental procedure will be fully reported in Ref. 14

\section{B. Neutron radiographies at ANTARES}

High resolution neutron radiographies were performed at the advanced neutron tomography and radiography experimental system (ANTARES) station at FRM II. The main goal of these investigations was to study the inhomogeneous zone visible on the rear side of the east door relief (see Fig. 4).
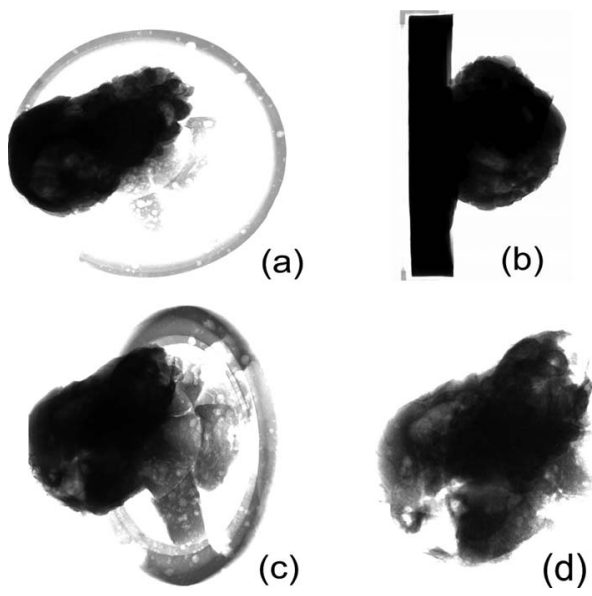

FIG. 5. Radiographies of the east head for four orientations of the relief flat base with respect to neutron direction: (a) $90^{\circ}$, (b) $0^{\circ}$, (c) $45^{\circ}$, and (d) same orientation as (c) but with different contrast.
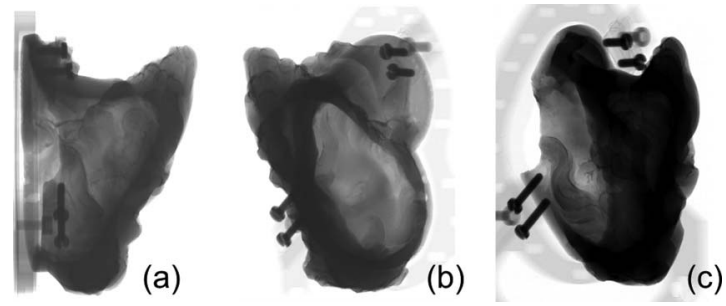

FIG. 6. Radiographies of the north head for four orientations of the relief flat base with respect to neutron direction, from left to right: (a) $90^{\circ}$, (b) $0^{\circ}$, and (c) $45^{\circ}$

The ANTARES station is positioned on a beam line facing the cold source of FRM II. Neutron fluxes of about $10^{8}$ and $2.6 \times 10^{7} \mathrm{n} / \mathrm{cm}^{2} \mathrm{~s}$ are available at the sample position for the two main collimation ratios $L / D=400$ and $L / D$ $=800$, respectively. Preliminarily short (few seconds) irradiation of the two reliefs showed that the decay time for a complete neutron tomography would have been in the order of three months, too long with respect to the constraint of a cooling time $<3$ days. For this reason, tomographic studies were not carried out. However, it must be stressed that a decay time in the order of several months could normally be handled for cultural heritage samples, allowing extended neutron tomography measurements. In the present case only short-exposure radiographic investigations with a collimation ratio $L / D=400$ were performed. The radiography images were collected with a CCD camera-based detector, 2048 $\times 2048$ pixels, set to view an area of $200 \times 200 \mathrm{~mm}^{2}$. The size of the neutron beam was about $150 \times 145 \mathrm{~mm}^{2}$.

Each sample was irradiated for about $200 \mathrm{~s}$, thus providing four $50 \mathrm{~s}$ radiographs each. Figures 5 and 6 show radiographies from the east head and north head.

\section{RESULTS AND DISCUSSION}

Results from PGAI/NR measurements on the heads are shown in Tables I and II. Table I reports results on the el-

TABLE I. Results of PGAI/NR analysis on East Head. Neutron irradiated zone numbering are: 1: laser cleaning, 2: uncleaned, 3: Rochelle salt cleaning, and 4: Rochelle salt cleaning zones. Third column reports the elements identified. The irradiated areas refer to the projection of the irradiated sample volume on the CCD camera of the transmission radiography setup.

\begin{tabular}{|c|c|c|c|}
\hline Position & Depth & Elements & Irradiated area $\left(\mathrm{mm}^{2}\right) \pm 0.1$ \\
\hline 1 & 1 & $\mathrm{Au}, \mathrm{Cu}$, and $\mathrm{Hg}$ & 1.2 \\
\hline 1 & 2 & $\mathrm{Au}, \mathrm{Cu}$, and $\mathrm{Hg}$ & 1.5 \\
\hline 1 & 3 & $\mathrm{Au}, \mathrm{Cu}$, and $\mathrm{Hg}$ & 1.8 \\
\hline 1 & 4 & $\mathrm{Au}, \mathrm{Cu}, \mathrm{Hg}$ & 1.9 \\
\hline 1 & Sum & $\mathrm{Au}, \mathrm{Cu}, \mathrm{Cl}$, and $\mathrm{Hg}$ & $\cdots$ \\
\hline 2 & Sum & $\mathrm{Cu}, \mathrm{Au}$, and $\mathrm{Cl}$ & $\cdots$ \\
\hline 3 & 1 & $\mathrm{Au}$ and $\mathrm{Cu}$ & 0.9 \\
\hline 3 & 2 & $\mathrm{Au}$ and $\mathrm{Cu}$ & 1.0 \\
\hline 3 & 3 & $\mathrm{Au}, \mathrm{Cu}$, and $\mathrm{Hg}$ & 1.1 \\
\hline 3 & Sum & $\mathrm{Au}, \mathrm{Cu}$, and $\mathrm{Hg}$ & $\cdots$ \\
\hline 4 & 1 & $\mathrm{Au}, \mathrm{Cu}$, and $\mathrm{Hg}$ & 0.9 \\
\hline 4 & 2 & $\mathrm{Au}, \mathrm{Cu}$, and $\mathrm{Hg}$ & 1.0 \\
\hline 4 & 3 & $\mathrm{Au}, \mathrm{Cu}$, and $\mathrm{Hg}$ & 1.1 \\
\hline 4 & Sum & $\mathrm{Au}, \mathrm{Cu}$, and $\mathrm{Hg}$ & $\cdots$ \\
\hline $3+4$ & Sum & $\mathrm{Au}, \mathrm{Cu}$, and $\mathrm{Hg}$ & $\cdots$ \\
\hline
\end{tabular}


TABLE II. Results of PGAI/NR analysis on north head. This relief was completely uncleaned. Detected elements and the referred position are reported.

\begin{tabular}{ccc}
\hline \hline Area & Position & Elements \\
\hline 1 & Brown zone on the beard & $\mathrm{Cu}$ and $\mathrm{K}$ \\
2 & Black zone near the beard-end & $\mathrm{Au}$ and $\mathrm{Cl}$ \\
3 & Gilded zone near the beard-end & $\mathrm{Au}, \mathrm{Cl}$, and $\mathrm{Cu}$ \\
& $\begin{array}{c}\text { Gilding and dark deposit between } \\
\text { the moustache and the nose-base }\end{array}$ & $\mathrm{Au}, \mathrm{Cl}, \mathrm{Cu}$, and $\mathrm{Hg}$ \\
\hline \hline
\end{tabular}

emental composition of the east head for the irradiated areas labeled in Fig. 3. Four positions were chosen covering the three cleaning-areas (positions 3 and 4 both refer to the Rochelle salt cleaned area). Each position was measured at different depths in $0.25 \mathrm{~mm}$ steps starting from the surface (labeled depth 1 in Table I). The $\mathrm{Au}, \mathrm{Cu}, \mathrm{Cl}$, and $\mathrm{Hg}$ elements were identified in the different areas at different depths. The irradiated areas were obtained through the neutron transmission image recorded by the charge-coupled device (CCD) camera. They were calculated through the profile of light areas in the radiographies performed during the simultaneous PGAI measurements. These profiles were compared with the image of the beam profile without sample: the difference between the beam profiles with and without the samples gives the irradiated sample area. The pixel size is $70 \times 70 \mu \mathrm{m}^{2}$ and the neutron beam spot area, as measured by the CCD, was approximately $4.41 \mathrm{~mm}^{2}$. The pixel illumination threshold was set to 20.4 of the gray scale with 255 corresponding to white and 0 to black. The study of irradiated area image is shown in Fig. 7.

In order to increase sensitivity to minority elements a
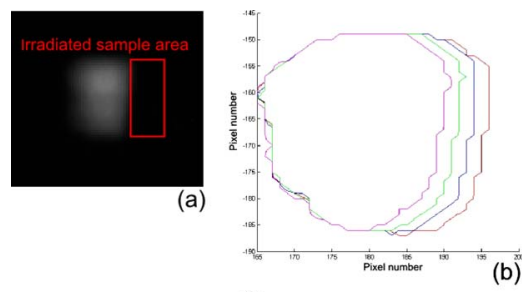

(b)
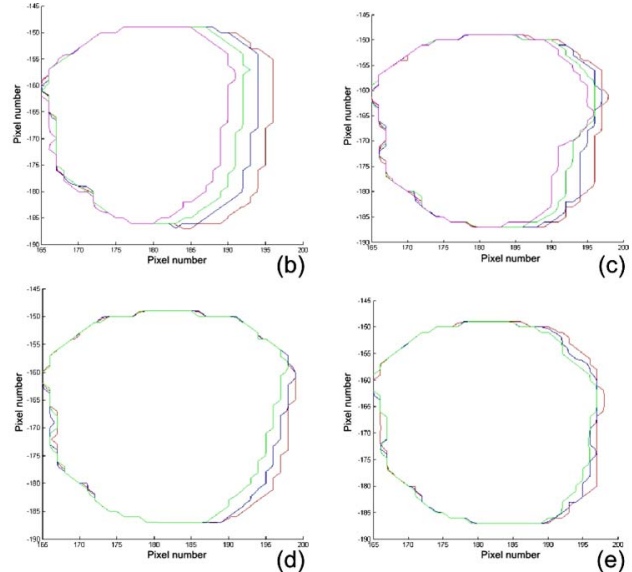

(c)

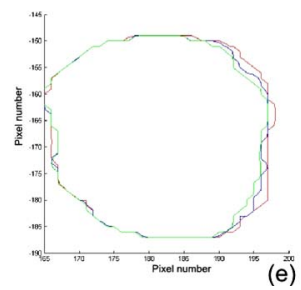

FIG. 7. (Color online) Beam-image radiography analysis. (a) Radiograph for the surface position 1 -depth 1 (cleaned by laser) carried out simultaneously to the PGAI measurements. The figure shows an approximation of the irradiated area of the sample (b) image of irradiated area in the position 1 performed during PGAI measurements. The axes reports the pixels labels starting from the upper-left corner: depth $1=$ red (number of illuminated pixels-NOP $=650)$, depth $2=$ blue $(\mathrm{NOP}=593)$, depth $3=$ green (NOP $=528)$, and depth $4=$ pink $(\mathrm{NOP}=472)$. (c) Image of irradiated area in the position 2: depth $1=\operatorname{red}(\mathrm{NOP}=696)$, depth $2=$ blue $(\mathrm{NOP}=659)$, depth 3 $=$ green $(\mathrm{NOP}=648)$, depth $4=$ pink and $(\mathrm{NOP}=634) ;(\mathrm{d})$ Image of irradiated area in the position 3: depth $1=$ red $(\mathrm{NOP}=722)$, depth $2=$ blue (NOP $=707)$, and depth $3=$ green $(\mathrm{NOP}=669)$. (e) Image of irradiated area in the position 4 : depth $1=\operatorname{red}(\mathrm{NOP}=713)$, depth $2=$ blue $(\mathrm{NOP}=689)$, and depth $3=$ green $(\mathrm{NOP}=670)$. sum of the spectra over all depths at the same position ("Sum" in Table I) was calculated. This procedure allowed identification of elements such as $\mathrm{Cl}$. In certain positions, for example position 2 , the beam irradiated a very low amount of the material and only the Sum results are shown. Chlorine was not detected in the areas (3 and 4) treated with Rochelle salts. Other elements, such as $\mathrm{Ca}, \mathrm{S}, \mathrm{C}, \mathrm{Si}, \mathrm{Al}, \mathrm{Fe}, \mathrm{O}$, and $\mathrm{Sn}$, although expected to be present in the uncleaned areas, were not detected because of their low $n$-gamma cross sections. In Table II qualitative results on elemental composition of the north head are shown. The relief is uncleaned and four positions were chosen for the PGAI/NR measurements.

For each sample position the measurements were performed at four different depths. The encrusted brown area of the beard did not present any trace of Chlorine compounds and was found to be mainly made of copper (I) oxide $(\mathrm{Cu}-$ prite). All other measurement points present clear traces of chlorine.

It has to be stressed that the quantitative determination of elemental and isotopic concentrations from PGAI/NR requires taking into account neutron attenuation and gamma self-absorption. The latter can be obtained by calculation of neutron and gamma transport in the case of complex shaped three-dimensional (3D) samples. Work is in progress to routinely address the above corrections for quantitative concentration analysis.

The analysis of the radiographic images carried out on the east head allowed revealing the bulk. The radiographies in Fig. 5(c) and 5(d) indicate clearly a lighter gray area in the nape. This could either indicate: (1) an empty part of the bronze head or (2) a smaller thickness of the sample. In order to understand the origin of this feature, a procedure combining 3D laser scanning and the present neutron radiographies was implemented as follows. Two points along the $x$ coordinate (the gray gradient analysis segment $\mathrm{AB}$ - see Fig. 8) having the same external sample thickness (as measured by 3D laser scanning) are considered. A cavity would correspond to a larger neutron transmission (lighter gray). In Fig. 8 (a) consider the segment $\mathrm{AB}$ generated by the intersection of the radiographic plane RP and a plane NB perpendicular to RP and parallel to the neutron beam direction. The graygradient along $\mathrm{AB}$ is reported in Fig. 8(b). It is related to the transmission as a function of the $x$ coordinate along $\mathrm{AB}$. The effective sample thickness for the measurement points is obtained by means of conventional 3D laser scanning of the head. A 3D virtual model of the surface is shown in Fig. 8(c), corresponding to the same sample orientation as in the neutron radiograph of Fig. 8(a). A virtual-cut [Fig. 8(d)] of this model along the previously defined plane NB allows to calculate the effective sample thickness along $x$, the coordinate of the $\mathrm{AB}$ [Fig. 8(e)].

A comparison of the neutron transmission and effective sample thickness as a function of $x$ shows that in the range $0.7 \mathrm{~cm} \leq x \leq 3.0 \mathrm{~cm}$ the transmission is higher than that in the range $5.0 \mathrm{~cm} \leq x \leq 6.0 \mathrm{~cm}$. This supports the hypothesis that the lighter area in the nape is due to the presence of a cavity. However presence of inhomogeneities with smaller cross section in the elemental composition cannot be excluded. 

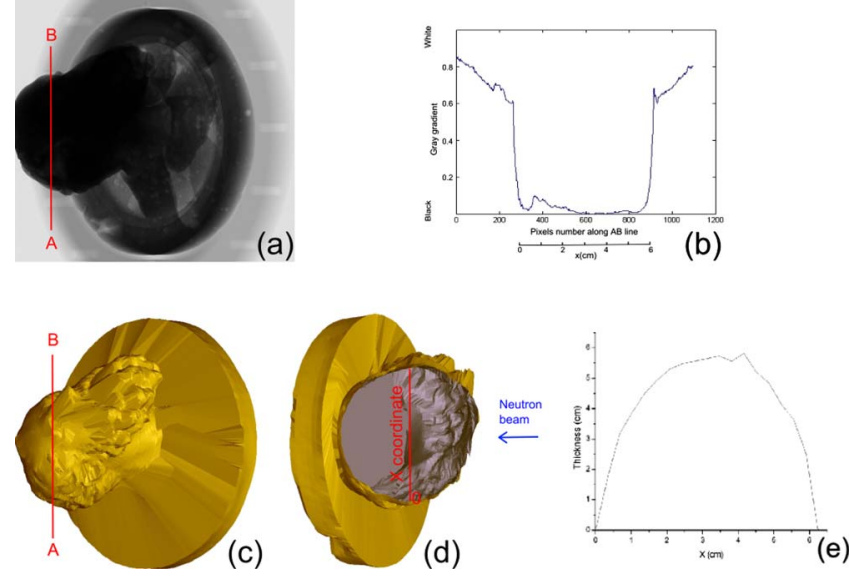

(e)

FIG. 8. (Color online) Analysis of the $45^{\circ}$ neutron radiographic image of the east head: (a) NR with the gray gradient analysis segment $A B$ generated by the intersection of the radiographic plane RP and a plane NB perpendicular to RP and parallel to the neutron beam direction; (b) Gray gradient in the radiography (a) along $x$ coordinate of the $\mathrm{AB}$ segment. In the plot, 1 correspond to white (complete transmission), 0 corresponds to black (complete attenuation). The horizontal axis report the pixel label, along the $\mathrm{AB}$ segment and the corresponding $x$ coordinate. (c) 3D image model obtained by laser scanning; (d) virtual-cut to this model along the plane NB passing through the segment $\mathrm{AB}$; and (e) effective sample thickness along the $\mathrm{AB}$ segment.

\section{CONCLUSIONS}

The application of the PGAI/NR technique, obtained through the combination of PGAI/NR provided the elemental composition profiles of subsurface corrosion compounds of the two reliefs, in the gilding/corrosion interface, although employing a reduced neutron beam exposure that guaranteed a cooling time of three days.

As far as the east head is concerned, the experiment allowed identification of the following elements: $\mathrm{Cu}, \mathrm{Au}, \mathrm{Hg}$, and $\mathrm{Cl}$ in the uncleaned part; $\mathrm{Cu}, \mathrm{Au}$, and $\mathrm{Hg}$ in the area cleaned by Rochelle salts; and $\mathrm{Cu}, \mathrm{Au}, \mathrm{Hg}$, and $\mathrm{Cl}$ in the area cleaned by laser ablation. The presence of $\mathrm{Cl}$ in the uncleaned part is not surprising, whereas $\mathrm{Cl}$ presence in the area cleaned by laser ablation is relevant and provides valuable information for future conservation of the artifact. In fact chlorine compounds represent a dangerous component as far as the corrosion processes is concerned. In the long term such compounds can seriously alter and damage the gilding layer if the piece were to be exposed to an environment with a high relative humidity.

High resolution neutron radiographies provided the extension of the remelting area in the east head. Such remelting appears to have a great extension in depth, from the flat base up to the front face of the relief. This suggests that, because the original melting was not satisfactory, the sculptor made a second one. The pouring of metal inside the original cavity from the rear side accumulated the casting in the front part of the head leaving part of the original cavity empty in corre- spondence of the nape. In the case of the north head it was possible to identify the following elements: $\mathrm{Cu}, \mathrm{Au}, \mathrm{Hg}, \mathrm{Cl}$, and $\mathrm{K}$. These typically form the gilded layer and pollution incrustations.

Results from these investigations are expected to provide valuable information to assist restorators in selecting the most suitable microclimatic conditions for the exhibition environment of the whole east door and setting up future conservation work for the north door.

\section{ACKNOWLEDGMENTS}

Work performed with financial support by the European Community "New and Emerging Science and Technology" under Contract No. 15311. The authors wish to thank the Opera Santa Maria Del Fiore and Soprintendenza Speciale per il patrimonio Storico, Artistico, Etnoantropologico e per il Polo Museale della città di Firenze for having made possible the analysis on the Ghiberti's reliefs. This work was performed under the agreement in force between the Ministero per i Beni e le Attività Culturali (MIBAC), the Università degli Studi di Roma 'Tor Vergata' and Università degli Studi Milano-Bicocca (2007) for neutron spectroscopy. Special thanks to the MIBAC team: Dr. A. P. Recchia, Dr. R. Binacchi, Dr. S. Celentino, and Dr. M. T. Didedda.

${ }^{1}$ E. Mello, P. Parrini, M. Matteini, A. Moles, G. Rocchi, A. Bartolozzi, L. Giorgi, and G. Giusgredi, Metodo e Scienza-Operativa Ricerca nel Restauro (Method and Science-Operative Research in the Restoration) (Sansoni, Florence, 1982), pp. 168-202.

${ }^{2}$ P. Fiorentino, M. Marabelli, M. Matteini, and A. Moles, Studies in Conservation 27, 145 (1982).

${ }^{3}$ E. Mello, Gold Bull. 19, 123 (1986).

${ }^{4}$ S. Siano, M. Miccio, P. Bertelli, F. Marinelli, S. Mugnaini, and G. Garagnani. Studio sulla tecnica di fusione dei rilievi della Porta del ParadisoStudy of the fusion technique of Gate of Paradise relief, Schede di restauro-Restoration Schedule.

${ }^{5}$ S. Siano, R. Salimbeni, R. Pini, A. Giusti, and M. Matteini, J. Cultural Heritage 4, 140 (2003).

${ }^{6}$ A. Giusti and M. Matteini, The Gilded Bronze Paradise Doors by Ghiberti in the Florence Baptistery (ICOMOS, Germany, 1997).

${ }^{7}$ M. Matteini, C. Lalli, I. Tosini, A. Giusti, and S. Siano, J. Cultural Heritage 4, 147 (2003).

${ }^{8}$ G. Gorini and the Ancient Charm Collaboration Nuovo Cimento 30, 47 (2007).

${ }^{9}$ Z. Kis, T. Belgya, L. Szentmiklsi, Zs. Kasztovsky, P. Kudejova, and R. Schulze. Archaeometry Workshop 1, 41 (2008).

${ }^{10}$ T. Belgya, Z. Kis, L. Szentmiklsi, Z. Kasztovszky, P. Kudejova, R. Schulze, T. Materna, G. Festa, and P. A. Caroppi, J. Radioanal. Nucl. Chem. 278, 751 (2008).

${ }^{11}$ T. Belgya, Z. Kis, L. Szentmiklsi, Z. Kasztovszky, G. Festa, L. Andreanelli, M. P. De Pascale, A. Pietropaolo, P. Kudejova, R. Schulze, and T. Materna, J. Radioanal. Nucl. Chem. 278, 713718 (2008).

${ }^{12}$ P. Kudejova, L. Canella, R. Schulze, J. Jolie, N. War, and A. Türler, AIP Conf. Proc. 1090, 9 (2009).

${ }^{13}$ P. Kudejova, L. Canella, R. Schulze, J. Jolie, A. Türler, T. Belgya, L. Szentmiklósi, Z. Kis, M. Ebert, FRM II Annual Report 2008.

${ }^{14}$ R. Schulze, L. Canella, P. Kudejova, J. Jolie, A. Türler, G. Festa, S. Porcinai. PGAI/NT measurement of cultural heritage reliefs at the FRMII research facility (unpublished). 